\title{
Atitudes da População Portuguesa em Relação à Homoparentalidade
}

\author{
Portuguese Attitudes toward Homosexual Parenting
}

\author{
Pedro Alexandre Costa ${ }^{*}, a, c$, Sara Caldeira ${ }^{a}$, Inês Fernandes ${ }^{a}$, Cláudia Rita $^{b}$, \\ Henrique Pereira $^{c} \&$ Isabel Leal ${ }^{a}$ \\ ${ }^{a}$ Instituto Superior de Psicologia Aplicada, Lisboa, Distrito de Lisboa, Portugal, ${ }^{b}$ Instituto Piaget, Almada, Portugal \\ \& ${ }^{C}$ Universidade da Beira Interior, Covilhã, Portugal
}

\begin{abstract}
Resumo
O objetivo deste estudo foi avaliar as atitudes da população portuguesa em relação à homoparentalidade. Participaram 993 pessoas com idades entre os 18 e os 69 anos $(M=34 ; D P=11)$, respondendo a um questionário que incluiu uma vinheta descrevendo um casal heterossexual, um casal de lésbicas ou um casal gay que pretendia adotar. Foi pedido aos participantes que avaliassem os casais enquanto futuros pais, e se antecipavam dificuldades emocionais e sociais no desenvolvimento da criança. Apesar da maioria dos participantes apresentar uma atitude favorável à homoparentalidade, os resultados revelaram uma atitude mais favorável em relação ao casal heterossexual. Os participantes anteciparam mais problemas emocionais e sociais nas crianças adotadas por um casal de duas mulheres, e mais ainda por um casal de dois homens.
\end{abstract}

Palavras-chave: Homoparentalidade, adoção, casais do mesmo sexo, atitudes.

\begin{abstract}
The aim of this study was to explore Portuguese population attitude toward parenting by gay men and lesbians. Nine hundred ninety three participants, aged between 18 and $69(M=34 ; S D=11)$, filled in a questionnaire that included a vignette depicting a heterosexual couple, a lesbian couple or a gay couple wishing to adopt. Participants were asked to rate the couple as prospective parents, and if they anticipated emotional or social problems for the children. Although most participants held a positive attitude toward gay and lesbian parents, the results revealed a more favorable attitude toward heterosexual couples. Participants anticipated more emotional and social problems in children adopted by a lesbian couple, and even more so by a gay couple.

Keywords: Homoparenting, adoption, same-sex couples, attitudes.
\end{abstract}

De acordo com os censos Norte-Americanos, no ano de 2000 estimava-se que mais de 150 mil casais do mesmo sexo tinham filhos menores de 18 anos, sendo que cerca de 270 mil crianças cresciam em famílias com dois pais ou duas mães e cerca de 540 mil com um pai gay ou uma mãe lésbica (United States Census Bureau [US Census Bureau], 2003). Outras estimativas comunitárias revelaram que aproximadamente uma em cada cinco lésbicas e um em cada nove homens gays assumiam funções parentais (Bryant \& Demian, 1994), estimando-se que o número de crianças a crescer numa família homoparental se situava entre os seis e os 14 milhões (Patterson, 2002; Patterson \& Friel, 2000; Ryan \& Martin, 2000).

\footnotetext{
" Endereço para correspondência: Unidade de Investigação em Psicologia e Saúde, Instituto Superior de Psicologia Aplicada, Rua Jardim do Tabaco, 34, Lisboa, Distrito de Lisboa, Portugal 1149-041. E-mail: pcosta@ispa.pt
}

Na verdade, pessoas gays, lésbicas e bissexuais sempre assumiram funções parentais, começando a assistir-se nas últimas três décadas ao fenómeno a que os investigadores apelidaram de lesbian and gay baby boom e que consiste na constituição de famílias lésbicas e gays planeadas. Este fenómeno, que inicia nos Estados Unidos, verifica-se também em diversos países Europeus como é o caso da Holanda ou Bélgica (Bos, van Balen, \& van den Boom, 2005; Brewaeys, 2001).

Em Portugal estima-se que a maioria das famílias homoparentais sejam famílias reconstituídas após a divulgação da orientação sexual do pai ou da mãe, à semelhança do que acontece em outros países onde o enquadramento legal não permite o acesso por pessoas gays e lésbicas a formas alternativas de parentalidade, nomeadamente em Itália (Lelleri, Prati, \& Pietrantoni, 2008), ou em países onde esta realidade é ainda recente como é o caso de Espanha (González \& López, 2009). 
A escassez de estudos empíricos com estas famílias dificulta mais ainda uma estimativa do número de famílias, assim como a sua caracterização. Estudos comunitários recentes estimam que 3\% das pessoas gays, lésbicas e bissexuais e $8 \%$ dos casais do mesmo sexo tinham filhos, não existindo, contudo, uma estimativa real da dimensão da população Lésbica, Gay, Bissexual e Transgénero (LGBT) Portuguesa (Costa, Pereira, \& Leal, 2013). Não obstante, inferindo a partir de dados norte-americanos que indicam que cerca de $5 \%$ da população maior de idade se identifica como gay, lésbica, bissexual ou transgénero (Gagnon, Laumann, Michael, \& Michaels, 1994), será possível inferir a dimensão da população LGBT Portuguesa. De acordo com os censos de 2001, habitavam em Portugal cerca de $8 \mathrm{mi}$ lhões de pessoas maiores de 20 anos (Instituto Nacional de Estatística, 2002). Assim, 5\% seriam aprximadamente 400 mil pessoas lésbicas, gays e bissexuais. Se desta população retirarmos $3 \%$ a $8 \%$, poderemos esperar uma dimensão aproximada de famílias homoparentais em Portugal entre 12 e 32 mil. Este número incluiria, então, famílias reconstituídas após a divulgação da homossexualidade do pai ou da mãe, e famílias planeadas, ainda que maioritariamente monoparentais, de mães lésbicas e pais gays.

\section{Atitudes em Relação a Pessoas Homossexuais}

As atitudes em relação às famílias homoparentais assentam, em grande parte, em atitudes em relação às próprias pessoas lésbicas, gays e bissexuais. A literatura tem revelado que as atitudes negativas contra pessoas homossexuais (homonegativas) são comuns e frequentes nas sociedades ocidentais (Herek, 2000a; Kite \& Whitley, 2003). Contudo, a atitude em relação a pessoas homossexuais não é um conceito simples, dividindo-se em três principais categorias: (a) o medo ou repulsa por pessoas homossexuais; (b) a avaliação dos atos homossexuais como desviantes ou patológicos; e (c) as atitudes em relação aos direitos das pessoas homossexuais, categoria assente numa perspetiva tradicional dos papéis de género (Herek, 2004).

As pessoas que revelam atitudes homonegativas são com frequência pessoas que mantém atitudes mais sexistas, com uma visão tradicional de família nuclear, acreditam que a homossexualidade é uma escolha do indivíduo, mantêm uma maior religiosidade e uma identificação política mais conservadora (Davies, 2004; Herek, 2000a; Nagoshi et al., 2008). Tem-se também observado que os homens são mais homonegativos do que as mulheres, e com maior intensidade em relação a homens gays do que a mulheres lésbicas (Costa \& Davies, 2012; Herek, 2000b; Kite \& Whitley, 2003) Estas atitudes fundamentam, assim, as atitudes negativas em relação às famílias homoparentais (Crawford \& Solliday, 1996; McLeod, Crawford, \& Zechmeister, 1999).

\section{Atitudes em Relação à Homoparentalidade}

Victoria Clarke (2001) avaliou os argumentos mais frequentemente utilizados contra a homoparentalidade na comunicação social e em focus groups com estudantes universitários, tendo identificado seis principais categorias: (a) com base em crenças religiosas; (b) com base na impossibilidade biológica de reprodução; (c) com base no egoísmo dos pais/mães; (d) com base na falta de referências de género; (e) com base no desenvolvimento da orientação sexual; e (f) com base na vitimização e discriminação das crianças. Estas seis categorias dividem-se ainda em dois tipos de argumentos: argumentos que reforçam a imoralidade de pais gays e mães lésbicas, e argumentos que sublinham os efeitos negativos de crescer numa família homoparental.

A par da crescente visibilidade social e aumento do interesse científico sobre as famílias homoparentais, as atitudes têm vindo a sofrer alterações. Os estudos da década de 1990 com estudantes universitários revelaram baixos ou médios níveis de homonegatividade, mas perceções negativas de famílias homoparentais. O estudo de Crawford e Solliday (1996) revelou que os estudantes universitários não só detinham atitudes negativas em relação aos casais homossexuais que pretendiam adotar e tendiam a atribuir com menor frequência a custódia de uma criança a estes casais, como justificavam estas atitudes na avaliação de instabilidade dos casais homossexuais. Resultados semelhantes foram encontrados com estudantes universitários de Psicologia (Fraser, Fish, \& Mckenzie, 1995; King \& Black, 1999; Money \& Cain, 1997). Contudo, em estudos em que não foram encontradas estas diferenças, os participantes revelaram preocupação com a possibilidade de estas crianças serem vitimizadas na escola, e serem confrontadas com maiores dificuldades no seu dia a dia (Bliss \& Harris, 1999; McLeod et al., 1999). Um outro estudo mais recente, de origem Australiana, revelou que os estudantes de Serviço Social tinham uma atitude favorável em relação à homoparentalidade, elevado conhecimento sobre famílias homoparentais e baixo nível de homonegatividade (Camilleri \& Ryan, 2006).

Resultados semelhantes foram observados com estudantes de áreas psicossociais Portugueses, não se tendo encontrado diferenças significativas na avaliação de casais homossexuais e heterossexuais. Contudo, foi observado que os participantes antecipavam maiores dificuldades sociais em crianças adotadas por pessoas homossexuais, assim como uma maior probabilidade de virem a ser, também elas, adultos homossexuais (Gato, Fontaine, \& Carneiro, 2010). Um outro estudo Português com uma amostra universitária revelou claramente a existência de atitudes negativas em relação a famílias homoparentais (Xavier, Mendes, Martins, \& Fernandes, 2011). A nível Europeu, na média dos países-membros, apenas 32\% são favoráveis à adoção de crianças por parte de casais do mesmo sexo, ainda que $44 \%$ se revelem favoráveis à extensão do casamento a estes casais. Em Portugal, $29 \%$ das pessoas revelaram-se favoráveis ao acesso ao casamento por casais do mesmo sexo, e apenas $19 \%$ à adoção por estes casais (Commissioner for Human Rights, 
2011). Estes dados foram recolhidos em 2006, quatro anos antes do casamento civil em Portugal ter sido estendido a casais do mesmo sexo. A adoção de crianças e o acesso a reprodução medicamente assistida continua, contudo, vetada a estes casais.

\section{O Presente Estudo}

O objetivo do presente estudo foi desenvolver a investigação empírica em Portugal sobre as atitudes em relação às famílias homoparentais por parte de pessoas heterossexuais, e explorar os seus argumentos contra estas famílias. Com este objetivo foram colocados os seguintes problemas de investigação: (a) Serão as atitudes em relação a casais de sexo oposto e casais do mesmo sexo diferentes?; (b) Quais são os argumentos contra a adoção por casais do mesmo sexo?; (c) Serão estas atitudes diferentes em homens e em mulheres?; (d) Serão estas atitudes diferentes com base em crenças religiosas?

\section{Método}

\section{Participantes}

A amostra consistiu em 993 participantes (27\% do sexo masculino e $73 \%$ do sexo feminino), heterossexuais, de nacionalidade Portuguesa, com idades compreendidas entre os 18 e os 69 anos $(M=34, D P=11)$. Trezentos e trinta e três participantes responderam ao questionário 1 (casal heterossexual), 359 participantes responderam ao questionário 2 (casal de duas mulheres), e 301 participantes responderam ao questionário 3 (casal de dois homens). A maioria da amostra foi constituída por pessoas solteiras (55\%), com elevada qualificação académica (licenciatura: $43 \%$, pós-graduação: $44 \%$ ), sem filhos (67\%), e provenientes das cidades mais populosas (36\% de Lisboa, $10 \%$ do Porto, $6 \%$ de Setúbal). 55\% dos participantes identificaram-se como Católicos, $11 \%$ espirituais mas não religiosos, e $31 \%$ ateus.

\section{Instrumentos}

Juntamente com um questionário demográfico, foi apresentado a cada participante uma de três vinhetas na qual é descrita uma família candidata à adoção de uma criança. Foi então pedido aos participantes que avaliassem as qualidades desta família como futuros pais/mães de uma criança respondendo a quatro questões. Através de um desenho de investigação quasi-experimental foi apresentado a cada participante apenas uma família constituída por um casal heterossexual, por um casal de dois homens ou por um casal de duas mulheres. Cada casal foi descrito como tendo uma relação longa e estável e com forte desejo de parentalidade. Foi também descrito como gozando de estabilidade financeira e profissional, de um bom suporte social, e estabilidade emocional. Esta vinheta foi construída a partir do trabalho de Camilleri e Ryan (2006) de acordo com os objetivos deste estudo. A adaptação da vinheta foi submetida a análise da sua validade facial através de um focus group com técnicos de Psicologia familiarizados com investigação na área da Parentalidade por forma a garantir que a história era clara, objetiva, e descrevia os aspetos mais importantes da caracterização familiar. A versão final da vinheta é apresentada em anexo (Anexo).

Foi pedido aos participantes que após lerem a história respondessem a quatro questões: (a) "Considera que a 'Pessoa A' e a 'Pessoa B' serão bons pais (ou mães)?; (b) "Pensa que se a 'Pessoa A' e a 'Pessoa B' adotarem, a criança poderá estar em risco de problemas emocionais?"; (c) "Pensa que se a 'Pessoa A' e a 'Pessoa B' adotarem, a criança poderá ser gozada ou rejeitada pelos colegas na escola?”; e (d) “Considera a 'Pessoa A' e a 'Pessoa B' bons candidatos (ou candidatas) a adotar uma criança? Porquê?". As primeiras três questões foram medidas numa escala de Likert de 4 pontos (seguramente não, provavelmente não, provavelmente sim, seguramente sim), e os nomes foram atribuídos conforme o casal fosse heterossexual, gay ou lésbico. A última questão foi de resposta aberta, permitindo que os participantes descrevessem a sua perceção da família e os seus argumentos em relação à parentalidade.

\section{Procedimentos}

Os participantes foram recrutados através da colocação de anúncios na internet, nomeadamente em fóruns de diversos tipos, grupos e listas online, e através da criação de uma página no Facebook para este efeito. Os participantes foram então encaminhados para um website com o título "Atitudes da População Portuguesa sobre a Homoparentalidade", onde constava o nome e filiação dos investigadores e o objetivo do estudo. Neste website foram disponibilizados três links diferentes para o questionário, e os participantes foram informados que deveriam escolher apenas um destes e preencher apenas esse questionário. Por forma a controlar o número de respostas por questionário, a ordem dos links apresentados foi alterada semanalmente. No que diz respeito à prevenção do preenchimento de mais de um questionário por pessoa, não foi utilizado nenhum bloqueio ao Internet Protocol (IP), uma vez que no mesmo IP poderiam responder mais do que uma pessoa. Além disso, acreditamos que a extensão e o tempo de resposta do questionário demoveriam as pessoas de mais do que um preenchimento. Contudo, após a introdução das respostas no SPSS, versão 19 , os dados foram cuidadosamente analisados para detetar questionários duplicados. $\mathrm{O}$ método amostral utilizado garante a confidencialidade e anonimato de todos os participantes, desta forma permitindo que os participantes expressassem as suas opiniões sem constrangimentos.

\section{Resultados}

\section{Avaliação dos Casais Adotantes}

A totalidade dos participantes avaliou positivamente o casal heterossexual, enquanto que $27 \%$ afirmou seguramente que o casal duas mulheres seriam boas mães e $68 \%$ que provavelmente seriam. No caso do casal de dois 
Costa, P. A., Caldeira, S., Fernandes, I., Rita, C., Pereira, H. \& Leal, I. (2013). Atitudes da População Portuguesa em Relação à Homoparentalidade.

homens, $27 \%$ afirmaram que seriam bons pais e $67 \%$ que provavelmente seriam.

Para averiguar a existência de diferenças entre os grupos que avaliaram o casal heterossexual, o casal de duas mulheres, e o casal de dois homens, foram realizadas ANOVA one-way, com o tipo de família (hetero $\mathrm{x}$ lésbica $\mathrm{x}$ gay) como variável independente e as três questões como variáveis dependentes. Os resultados dos testes ANOVA revelaram um efeito (Tabela 1) do tipo de casal na antecipação de dificuldades emocionais $[F(2$ $992)=12,464, p<0,001]$ e sociais de crianças $[F(2,992)$ $=377,550, p<0,001]$. De acordo com os testes post-hoc de Tukey, os participantes anteciparam uma maior incidência de problemáticas em crianças adotadas por casais de dois homens ou de duas mulheres $(p<0,001)$ do que em casais heterossexuais, e uma maior antecipação de vitimização das crianças quando estas eram adotadas por um casal de duas mulheres $(p<0,001)$, e mais ainda quando adotadas por um casal de dois homens $(p=0,025)$.

Tabela 1

Média, Desvio Padrão e Resultados do Teste ANOVA

Tipo de casal

\begin{tabular}{lll}
\hline Heterossexual & Lésbico & Gay \\
\hline
\end{tabular}

\begin{tabular}{lccccccc}
\hline Qualidade parental & 333 & $1,89(0,32)$ & 359 & $1,80(0,59)$ & 301 & $1,81(0,60)$ & $\begin{array}{c}F(2,992)=2,916, \\
p=0,055\end{array}$ \\
Risco emocional da criança & 333 & $1,92(0,44)$ & 359 & $2,14(0,79)$ & 301 & $2,17(0,82)$ & $\begin{array}{c}F(2,992)=12,464, \\
p<0,001^{*}\end{array}$ \\
\begin{tabular}{l} 
Risco social da criança \\
\hline
\end{tabular} & 333 & $1,79(0,53)$ & 359 & $2,81(0,60)$ & 301 & $2,93(0,63)$ & $\begin{array}{c}F(2,992)=377,550, \\
p<0,001^{*}\end{array}$ \\
\hline
\end{tabular}

*Nota. Os resultados significativos são assinalados.

\section{Argumentos Contra a Homoparentalidade}

Apesar de os resultados obtidos revelarem que a maioria das pessoas apresenta uma atitude favorável em relação à homoparentalidade, as diferenças encontradas na avaliação dos três casais são reveladoras da existência de negatividade em relação a estas famílias. Por forma a compreender os motivos que justificam estas atitudes, apenas as respostas negativas à qualidade dos casais do mesmo sexo (questionários 2 e 3 ) foram avaliadas através de análise de conteúdo (Bardin, 1977). As respostas dadas pelos participantes foram analisadas e categorizadas, tendo emergido três categorias de resposta: 'críticas aos pais', 'preocupação com as crianças' e 'críticas à situação' (Tabela 2). Do total de 88 observações, $51 \%$ dizem respeito à menor qualidade parental percebida de casais do mesmo sexo, e o motivo mais evocado (14 observações) foi o da falta de papéis tradicionais de género: "A verdade é que milhares de estudos suportados cientificamente já comprovaram que, na grande maioria dos casos, a mãe proporciona mais carinho, afeto, apoio sentimental, paciência, compreensão e disponibilidade total às crianças. São, portanto, emocionalmente mais disponiveis [sic]". Neste caso, os papéis tradicionais de género dizem respeito ao papel do pai e da mãe, assumidos como complementares e, por esse motivo, fundamentais. Outros argumentos frequentemente evocados dizem respeito a uma infe- rioridade destes casais face a casais heterossexuais, como por exemplo: "Entre ficar numa instituição com carências afetivas, é preferivel ficar com pais homossexuais. Contudo a preferência terá de ser sempre dada aos casais heterossexuais [sic]".

Esta postura, apresentando uma crença de superioridade moral de pessoas heterossexuais, demonstra contudo alguma abertura face à parentalidade por parte de pessoas homossexuais. Em contraste, outros participantes revelam uma postura mais próxima de aversão aos próprios homossexuais sob a forma de patologização destes ou das suas relações, como pode ser observado na seguinte resposta: "também é do conhecimento geral que a maioria das relações homossexuais são de curta/média relação e que trocam frequentemente de parceiro o que também não é benéfico para a criança ver um dos pais com diferentes parceiros [sic]".

No que diz respeito aos argumentos relativos à preocupação com o bem-estar e desenvolvimento das crianças ( $42 \%$ das observações), os motivos mais frequentemente evocados agruparam-se em apenas três sub-categorias: 'experiências de vitimização / discriminação', 'problemas de desenvolvimento social e emocional' e 'não acesso à diferenciação e identificação de género'. A maioria dos participantes (15 observações) manifestou preocupação com as crianças poderem vir a ser vitimizadas pelos pares, como por exemplo: 
Psicologia: Reflexão e Crítica, 26(4), 790-798.

Tabela 2

Categorias e Sub-Categorias da Análise de Conteúdo

\begin{tabular}{llc}
\hline Categorias & \multicolumn{1}{c}{ Sub-categorias (Argumentos) } & $N^{0}$ observações \\
\hline Críticas aos pais & Complementaridade dos papéis de género & 14 \\
& Natureza / Biologia & 9 \\
& Estigmatização da homossexualidade & 8 \\
& Superioridade da heterossexualidade & 6 \\
& Valores familiares da sociedade & 4 \\
& Incapacidade parental & 3 \\
& Religião & 1 \\
Preocupação com as crianças & Vitimização / Discriminação & 15 \\
& Diferenciação / Identificação de género & 11 \\
& Desenvolvimento socioemocional & 11 \\
Críticas ao material & Preconceito da sociedade & 4 \\
& Realidade fatual & 1 \\
& Crítica da investigação & 1 \\
\hline
\end{tabular}

. . possam ser uns excelentes candidatos a adotar qualquer criança deste mundo, mas é certo que apesar da mente aberta que evolui ao passar dos tempos nas sociedades também existem muitas pessoas maldosas e as crianças possivelmente podem sofrer de bullying $[$ sic $]$.

Estes argumentos colocam a responsabilidade pelo heterossexismo da sociedade nos homens gays e mulheres lésbicas, desresponsabilizando a sociedade na promoção da igualdade e do respeito por todos os que a integram. Mesmo os participantes que evocam riscos desenvolvimentais ou emocionais para a criança, raramente concretizam quais estes seriam, em muitos casos associando-os a consequências emocionais das experiências de vitimização: "Não creio que seja emocionalmente bom para uma criança ter dois pais ou duas mães. Será gozada na escola e isso colocará ao nível psicológico na criança uma sensação de exclusão [sic]".

Finalmente, a terceira sub-categoria de argumentos que emergiu dos dados foi a preocupação com problemáticas ligadas à diferenciação de género, problemáticas suscitadas pela falta de uma figura materna e de uma figura paterna: "uma criança precisa de um pai e de uma mãe. Ambos desempenham funções diferentes na socialização e crescimento da criança, e ter dois pais é suprimir um dos papéis. Acredito que trará problemas à criança no futuro [sic]". Neste caso, a falta destas figuras de género é associada não só a problemáticas emocionais, como também à identificação de género da criança. Este receio faz parte de uma atitude que assenta nos papéis tradicionais de género associados ao ser homem e ao ser mulher.

\section{Comparação de Grupos}

Diferenças de Género. Para averiguar se homens e mulheres avaliaram de forma diferente a qualidade dos casais e a possibilidade de problemáticas da criança foram conduzidos testes $t$-student para amostras independentes, para cada uma destas questões (Tabela 3). Na avaliação do casal heterossexual não foram encontradas diferenças significativas entre homens e mulheres. Contudo, no cenário do casal de duas mulheres, os homens avaliaram mais negativamente o casal adotante $(p<0,001)$ e anteciparam maiores dificuldades emocionais da criança $(p<0,001)$ do que as mulheres. Resultados semelhantes foram encontrados no cenário do casal de dois homens, em que os homens avaliaram mais negativamente o casal adotante $(p<0,001)$ e anteciparam maiores dificuldades da criança $(p<0,001)$ do que as mulheres. Apesar de não terem sido encontradas diferenças de género no que diz respeito à antecipação de problemas sociais, é de salientar que tanto homens como mulheres obtiveram um resultado médio próximo de 3 , o que equivale à afirmação de que as crianças adotadas por um casal do mesmo sexo 'provavelmente' serão vítimas de rejeição pelos pares. 
Costa, P. A., Caldeira, S., Fernandes, I., Rita, C., Pereira, H. \& Leal, I. (2013). Atitudes da População Portuguesa em Relação à Homoparentalidade.

Tabela 3

Média, Desvio Padrão e Teste t de Student por Género

\begin{tabular}{|c|c|c|c|c|c|c|c|c|c|}
\hline & \multicolumn{9}{|c|}{ Tipo de casal } \\
\hline & \multicolumn{3}{|c|}{ Heterossexual } & \multicolumn{3}{|c|}{ Lésbico } & \multicolumn{3}{|c|}{ Gay } \\
\hline & $\begin{array}{c}\text { homens } \\
(n=89)\end{array}$ & $\begin{array}{c}\text { mulheres } \\
(n=244)\end{array}$ & & $\begin{array}{c}\text { homens } \\
(n=89)\end{array}$ & $\begin{array}{c}\text { mulheres } \\
(n=270)\end{array}$ & & $\begin{array}{c}\text { homens } \\
(\mathrm{n}=88)\end{array}$ & $\begin{array}{c}\text { mulheres } \\
(n=213)\end{array}$ & \\
\hline $\begin{array}{l}\text { Qualidade } \\
\text { parental }\end{array}$ & $\begin{array}{c}1,83 \\
(0,38)\end{array}$ & $\begin{array}{c}1,91 \\
(0,31)\end{array}$ & $\begin{array}{c}t(331)= \\
1,837, p=0,097\end{array}$ & $\begin{array}{c}1,99 \\
(0,82)\end{array}$ & $\begin{array}{c}1,73 \\
(0,48)\end{array}$ & $\begin{array}{c}t(357)= \\
3,578, \\
p<0,001^{*}\end{array}$ & $\begin{array}{c}1,99 \\
(0,74)\end{array}$ & $\begin{array}{c}1,73 \\
(0,52)\end{array}$ & $\begin{array}{c}t(299)=3,417 \\
p=0,001^{*}\end{array}$ \\
\hline $\begin{array}{l}\text { Risco } \\
\text { emocional } \\
\text { da criança }\end{array}$ & $\begin{array}{c}1,97 \\
(0,49)\end{array}$ & $\begin{array}{c}1,90 \\
(0,42)\end{array}$ & $\begin{array}{c}t(331)= \\
1,182, p=238\end{array}$ & $\begin{array}{c}2,43 \\
(0,96)\end{array}$ & $\begin{array}{c}2,05 \\
(0,70)\end{array}$ & $\begin{array}{c}t(357)= \\
3,954, \\
p=0,001^{*}\end{array}$ & $\begin{array}{c}2,44 \\
(0,87)\end{array}$ & $\begin{array}{c}2,05 \\
(0,77)\end{array}$ & $\begin{array}{c}t(299)=3,854 \\
p<0,001^{*}\end{array}$ \\
\hline $\begin{array}{l}\text { Risco social } \\
\text { da criança }\end{array}$ & $\begin{array}{c}1,79 \\
(0,53)\end{array}$ & $\begin{array}{c}1,79 \\
(0,53)\end{array}$ & $\begin{array}{c}t(281)= \\
0,006, p=0,995\end{array}$ & $\begin{array}{c}2,91 \\
(0,67)\end{array}$ & $\begin{array}{c}2,78 \\
(0,57)\end{array}$ & $\begin{array}{c}t(357)= \\
1,809, \\
p=0,071\end{array}$ & $\begin{array}{c}3,01 \\
(0,72)\end{array}$ & $\begin{array}{c}2,90 \\
(0,59)\end{array}$ & $\begin{array}{c}t(299)=1,436 \\
p=0,115\end{array}$ \\
\hline
\end{tabular}

*Nota. Os resultados significativos são assinalados.

Diferenças Religiosas. Para averiguar se as pessoas com diferentes crenças religiosas avaliaram de forma diferente os três casais recorreu-se novamente aos testes $t$-student para amostras independentes. Devido ao número reduzido de pessoas com diferentes crenças religiosas, foram apenas comparados os grupos de católicos e ateus (Tabela 4). Na avaliação do casal heterossexual não foram detetadas diferenças significativas em nenhuma das ques- tões. No cenário do casal de duas mulheres, foi observado que as pessoas católicas avaliaram mais negativamente as competências parentais do casal $(p=0,013)$, e anteciparam maiores dificuldades emocionais $(p=0,002)$ e sociais $(p=0,001)$ da criança adotada por este casal do que as pessoas ateias. Finalmente, no cenário do casal de homens, as pessoas católicas anteciparam maiores dificuldades emocionais da criança $(p<0,001)$ do que as pessoas ateias.

Tabela 4

Médias, Desvio Padrão e Teste t de Student por Afiliação Religiosa

\begin{tabular}{|c|c|c|c|c|c|c|c|c|c|}
\hline & \multicolumn{9}{|c|}{ Tipo de casal } \\
\hline & \multicolumn{3}{|c|}{ Heterossexual } & \multicolumn{3}{|c|}{ Lésbico } & \multicolumn{3}{|c|}{ Gay } \\
\hline & $\begin{array}{c}\text { católicos } \\
(n=185)\end{array}$ & $\begin{array}{l}\text { ateus } \\
(n=98)\end{array}$ & & $\begin{array}{l}\text { católicos } \\
(n=202)\end{array}$ & $\begin{array}{c}\text { ateus } \\
(n=103)\end{array}$ & & $\begin{array}{l}\text { católicos } \\
(n=156)\end{array}$ & $\begin{array}{l}\text { ateus } \\
(n=107)\end{array}$ & \\
\hline $\begin{array}{l}\text { Qualidade } \\
\text { parental }\end{array}$ & $\begin{array}{c}1,90 \\
(0,32)\end{array}$ & $\begin{array}{c}1,88 \\
(0,33)\end{array}$ & $\begin{array}{c}t(281)=0,629 \\
p=0,530\end{array}$ & $\begin{array}{c}1,86 \\
(0,62)\end{array}$ & $\begin{array}{c}1,67 \\
(0,62)\end{array}$ & $\begin{array}{c}t(303)=2,494 \\
p=0,01^{*}\end{array}$ & $\begin{array}{c}1,90 \\
(0,62)\end{array}$ & $\begin{array}{c}1,77 \\
(0,58)\end{array}$ & $\begin{array}{c}t(261)=1,726 \\
p=0,081\end{array}$ \\
\hline $\begin{array}{l}\text { Risco } \\
\text { emocional } \\
\text { da criança }\end{array}$ & $\begin{array}{l}1,94 \\
(0,47)\end{array}$ & $\begin{array}{c}1,90 \\
(0,39)\end{array}$ & $\begin{array}{c}t(281)=0,665 \\
p=0,506\end{array}$ & $\begin{array}{c}2,29 \\
(0,82)\end{array}$ & $\begin{array}{c}1,99 \\
(0,77)\end{array}$ & $\begin{array}{c}t(303)=3,109 \\
p<0,01^{*}\end{array}$ & $\begin{array}{c}2,38 \\
(0,83)\end{array}$ & $\begin{array}{l}1,98 \\
(0,74)\end{array}$ & $\begin{array}{c}t(261)=3,981 \\
p=0,001^{*}\end{array}$ \\
\hline $\begin{array}{l}\text { Risco social } \\
\text { da criança }\end{array}$ & $\begin{array}{l}1,75 \\
(0,55)\end{array}$ & $\begin{array}{c}1,79 \\
(0,50)\end{array}$ & $\begin{array}{c}t(281)=0,519 \\
p=0,605\end{array}$ & $\begin{array}{c}2,91 \\
(0,64)\end{array}$ & $\begin{array}{c}2,66 \\
(0,55)\end{array}$ & $\begin{array}{c}t(303)=3,383 \\
p=0,001^{*}\end{array}$ & $\begin{array}{c}3,00 \\
(0,63)\end{array}$ & $\begin{array}{c}2,92 \\
(0,57)\end{array}$ & $\begin{array}{c}t(261)=1,103 \\
p=0,271\end{array}$ \\
\hline
\end{tabular}

*Nota. Os resultados significativos são assinalados.

\section{Discussão}

Os resultados do presente estudo confirmaram a existência de diferenças na avaliação de famílias hetero parentais e homoparentais por pessoas heterossexuais. Apesar de não terem sido encontradas diferenças significativas na avaliação da qualidade parental, foram antecipadas maiores problemáticas emocionais e sociais em crianças adotadas por um casal do mesmo sexo do que por um casal de sexo oposto, resultado em linha com anteriores 
investigações (Bliss \& Harris, 1999; McLeod et al., 1999). Como esperado, os homens avaliaram mais negativamente as competências parentais dos casais do mesmo sexo e anteciparam maiores problemáticas emocionais nas crianças adotadas por estes do que as mulheres. A afiliação religiosa foi também uma variável importante na justificação das diferenças encontradas, tendo o grupo de pessoas católicas avaliado mais negativamente o casal de duas mulheres do que o grupo de pessoas ateias. Este grupo antecipou também maiores dificuldades emocionais em crianças adotadas por um casal do mesmo sexo, resultados de acordo com a literatura internacional (Crawford, McLeod, Zamboni, \& Jordan, 1999).

Em particular, na antevisão de problemas sociais das crianças, nomeadamente vitimização por parte dos colegas, os participantes revelaram maior preocupação com crianças com dois pais do que com duas mães. Esta diferença poderá estar relacionada com uma maior perceção de risco de discriminação de homens gays, o que está de acordo com a literatura sobre atitudes em relação a minorias sexuais que revelou de forma consistente maiores níveis de preconceito e homonegatividade em relação a homens gays do que a mulheres lésbicas (Herek, 2000b). Por outro lado, as mulheres, ainda que lésbicas, poderão ser percebidas como tendo as competências tradicionalmente associadas à maternidade o que poderia mitigar os efeitos da vitimização da criança.

Apesar dos participantes deste estudo terem revelado baixos níveis de negatividade em relação às famílias homoparentais, a possibilidade de as crianças poderem vir a ser vítimas de rejeição ou bullying pelos colegas foi uma preocupação evidente e independente da avaliação das qualidades do casal, do género dos participantes, ou da sua afiliação religiosa. Este resultado tem implicações importantes ao nível da integração das famílias homoparentais nos diferentes contextos sociais, e em particular no contexto escolar. É fundamental criar redes de suporte para as crianças que são filhas de pais gays ou mães lésbicas que frequentam a escola. De fato, uma forma privilegiada de garantir que a antecipação de problemas de bullying com estas crianças não será uma realidade é promovendo uma discussão aberta sobre a existência de diferentes orientações sexuais e sobre as diferentes configurações familiares, permitindo assim que as crianças de famílias homoparentais tenham um desenvolvimento e ajustamento psicológico e social adequado. Por outro lado, o contacto com pessoas com diferentes orientações sexuais tem-se mostrado ser uma variável importante na alteração das atitudes em relação a pessoas homossexuais (Herek \& Glunt, 1993), esperando-se que falar sobre diferentes configurações familiares, nomeadamente famílias homoparentais, surta o mesmo efeito.

Quando avaliadas as respostas à questão aberta sobre a qualidade parental percebida, os resultados evidenciaram uma maior percentagem de críticas aos casais do mesmo sexo do que argumentos baseados na preocupação com as crianças. Os argumentos com base na falta de figuras tradicionais de género, impossibilidade de gerar uma família de forma biológica, ou estigmatização da homossexualidade, mais frequentemente evocados, são reveladores de uma homonegatividade já sublinhados por Clarke (2001) na avaliação das representações nos meios de comunicação Britânicos. Estes argumentos são comuns na cultura ocidental e têm-se mantido ao longo dos anos e após inúmeros debates sobre a temática da homoparentalidade.

Segundo a mesma autora, estes argumentos servem a função de impedir que as pessoas homossexuais planeiem e constituam uma família, desta forma garantindo a superioridade moral das pessoas [e das famílias] heterossexuais (Clarke, 2001). No presente estudo, os argumentos apresentados desenvolvem-se em torno da incapacidade das pessoas homossexuais em assumir as funções parentais, tendo alguns participantes revelado atitudes explicitamente heterossexistas ao afirmarem que deve ser sempre dada preferência a casais heterossexuais aquando do processo de adoção. Em contraste, a investigação dedicada às competências parentais e desenvolvimento infantil em famílias homoparentais não confirma a existência de motivos que impeçam a constituição de família por parte de pessoas gays, lésbicas ou bissexuais (Anderssen, Amlie, \& Ytteroy, 2002; Patterson, 2006; Tasker, 2005). Pareceres da Associação Americana de Psicólogos e da Academia Americana de Pediatras afirmam, com base na evidência científica disponível, que o desenvolvimento das crianças e adolescentes é semelhante em famílias hetero e homoparentais considerando que mais importante que orientação sexual dos pais ou mães, são as interações e relações que se estabelecem na família para o desenvolvimento ótimo destas crianças (Paige, 2005; Perrin \& Committe on Psychosocial Aspects of Child and Family Health, 2002). Mais, um relatório elaborado pelo Conselho Europeu sobre os direitos de crianças concluiu que o bem-estar destas depende não só da dinâmica familiar em si, mas especialmente na proteção legal de que dispõem, sublinhando que a maior ameaça ao bem-estar e estabilidade das crianças é a discriminação de que são vítimas em países Europeus que não legitimam as suas famílias (Lowe, 2009). Não obstante, são ainda poucos os países Europeus que oferecem os mesmos direitos e proteção a famílias hetero e homoparentais - oito países no total - $\mathrm{e}$ as atitudes dos europeus em relação à qualidade parental de pessoas gays, lésbicas e bissexuais são ainda predominantemente negativas. Como referido, em 2006, $81 \%$ dos Portugueses não aceitavam que casais do mesmo sexo pudessem adotar crianças em iguais circunstâncias aos casais de sexo oposto, e 71\% afirmavam o seu desacordo com o acesso legal ao casamento (Commissioner for Human Rights, 2011).

\section{Limitações do Estudo}

Uma limitação importante deste estudo é a metodologia amostral utilizada. Tendo em conta as estatísticas apresentadas pelo Eurobarómetro, a maioria dos Portugue- 
Costa, P. A., Caldeira, S., Fernandes, I., Rita, C., Pereira, H. \& Leal, I. (2013). Atitudes da População Portuguesa em Relação à Homoparentalidade.

ses é ainda contra a adoção por parte de casais do mesmo sexo. Contudo, no presente estudo a grande maioria dos participantes mostrou-se favorável. Estes resultados sugerem cautela na sua interpretação, não se podendo por isso generalizar às atitudes da população Portuguesa. É possível que a amostra seja autosselecionada, tendo as pessoas que manifestam uma atitude mais favorável à adoção querido manifestar-se com maior frequência. Além disso, o perfil das pessoas utilizadoras da internet tende a revelar pessoas mais jovens, com maior nível de instrução e mais acesso à informação pelo que poderá constituir um enviesamento destes resultados em relação às atitudes da população em geral. Outro fator importante é a metade da amostra ser proveniente das três cidades Portuguesas mais urbanas, o que poderá também ter sido responsável pelas atitudes mais favoráveis à Homoparentalidade encontradas. É este um dos primeiros estudos empíricos realizados em Portugal, e o primeiro com uma amostra geral da população, sendo fundamental a continuidade da investigação nesta temática.

\section{Conclusão}

O presente estudo marcou o início da investigação empírica em Portugal sobre as atitudes das pessoas heterossexuais em relação a famílias homoparentais. Foi demonstrado existirem diferenças na avaliação da qualidade parental de casais heterossexuais, gays e de lésbicas, e que os homens e as pessoas católicas apresentam as atitudes menos favoráveis em relação a estas famílias. Através da análise dos argumentos apresentados contra a qualidade parental de casais do mesmo sexo observou-se a persistência de preconceito não só contra estas famílias mas também na estigmatização de pessoas gays, lésbicas e bissexuais. A maioria das pessoas manifestou o receio que as crianças adotadas por casais do mesmo sexo possam ser vitimas de rejeição e de discriminação pelos pares, o que reflete a necessidade de uma reflexão aprofundada sobre os mecanismos sociais que permitem uma potencial vitimização destas crianças e sobre as formas de intervenção nestas situações.

\section{Referências}

Anderssen, N., Amlie, C., \& Ytteroy, E. A. (2002). Outcomes for children with lesbian or gay parents: A review of studies from 1978 to 2000. Scandinavian Journal of Psychology, 43, 335-351.

Bardin, L. (1977). Análise de Conteúdo. Lisboa, Portugal: Edições 70.

Bliss, G. K., \& Harris, M. B. (1999). Teachers' views of students with gay or lesbian parents. Journal of Gay, Lesbian, and Bisexual Identity, 4, 149-171.

Bos, H. M. W., van Balen, F., \& van den Boom, D. C. (2005). Lesbian families and family functioning: An overview. Patient Education and Counseling, 59, 263-275.

Brewaeys, A. (2001). Review: Parent-child relationships and child development in donor insemination families. Human Reproduction Update, 7, 38-46.
Bryant, A. S., \& Demian (1994). Relationship characteristics of American gay and lesbian couples: Findings from a national survey. Journal of Gay \& Lesbian Social Services, 1, 101-117.

Camilleri, P., \& Ryan, M. (2006). Social work students' attitudes toward homosexuality and their knowledge and attitudes toward homosexual parenting as an alternative family unit: An Australian study. Social Work Education, 25, 288-304.

Clarke, V. (2001). What about the children? Arguments against lesbian and gay parenting. Women's Studies International Forum, 24, 555-570.

Commissioner for Human Rights. (2011). Discrimination on grounds of sexual orientation and gender identity in Europe. Strasbourg, France: Council of Europe Publishing.

Costa, P. A., \& Davies, M. (2012). Portuguese adolescents' attitudes toward sexual minorities: Transphobia, homophobia and gender role beliefs. Journal of Homosexuality, 59, 1424-1442.

Costa, P. A., Pereira, H., \& Leal, I. (2013). Social, psychological and demographic data of LGBT people in Portugal. Manuscrito em elaboração.

Crawford, I., McLeod, A., Zamboni, B. D., \& Jordan, M. B. (1999). Psychologists' attitudes toward gay and lesbian parenting. Professional Psychology: Research and Practice, 30, 394-401.

Crawford, I., \& Solliday, E. (1996). The attitudes of undergraduate college students toward gay parenting. Journal of Homosexuality, 30, 63-77.

Davies, M. (2004). Correlates of negative attitudes toward gay men: Sexism, male role norms, and male sexuality. Journal of Sex Research, 41, 259-266.

Fraser, I., Fish, T., \& Mackenzie, T. (1995). Reactions to child custody decisions involving homosexual and heterosexual parents. Canadian Journal of Behavioral Science, 27, 52-63.

Gagnon, J., Laumann, E., Michael, R., \& Michaels, S. (1994). The social organization of sexuality. Chicago, IL: University of Chicago Press.

Gato, J. C., Fontaine, A. M., \& Carneiro, N. S. (2010, fev.). Perceção de futuros profissionais de áreas psicossociais sobre o desenvolvimento psicológico de crianças educadas em famílias homoparentais. Trabalho apresentado no VII Simpósio Nacional de Investigação em Psicologia, Universidade do Minho, Braga, Portugal.

González, M. M., \& López, F. (2009). Relaciones familiares y vida cotidiana de niños y niñas que viven con madres lesbianas o padres gays. Cultura y Educación, 21, 417-428.

Herek, G. M. (2000a). The psychology of sexual prejudice. Current Directions in Psychological Science, 9, 19-22.

Herek, G. M. (2000b). Sexual prejudice and gender: Do homosexuals' attitudes toward lesbian and gay men differ? Journal of Social Issues, 56, 251-266.

Herek, G. M. (2004). Beyond "homophobia": Thinking about sexual stigma and prejudice in the twenty-first century. Sexuality Research and Social Policy, 1, 6-24.

Herek, G. M., \& Glunt, E. K. (1993). Interpersonal contact and heterosexuals' attitudes toward gay men: Results from a national survey. The Journal of Sex Research, 30, 239-244.

Instituto Nacional de Estatística. (2002, jan.). Censos 2001. Resultados provisórios. Lisboa, Portugal: Autor. Recuperado em $1^{\circ}$ dezembro, 2011, de http://www.ine.pt/

King, B. R., \& Black, K. N. (1999). College students' percetual stigmatization of the children of lesbian mothers. American Journal of Orthopsychiatry, 69, 220-227.

Kite, M. E., \& Whitley, B. E. (2003). Do heterosexual women and men differ in their attitudes toward homosexuality? A 
conceptual and methodological analysis. In L. D. Garnets \& D. C. Kimmel (Eds.), Psychological perspetives on lesbians, gay, and bisexual experiences (pp. 165-187). New York: Columbia University Press.

Lelleri, R., Pratti, G., \& Pietrantoni, L. (2008). Omogenitorialità: I risultati di una ricerca italiana. Difesa Sociale, 4, 71-84.

Lowe, N. (2009, September). A study into the rights and legal status of children being brought up in various forms of marital or non-marital partnerships and cohabitation. Committee of Experts on Family Law. Retrieved December 1, 2011, from http://www.coe.int/

McLeod, A. C., Crawford, I., \& Zechmeister, J. (1999). Heterosexual undergraduates' attitudes toward gay fathers and their children. Journal of Psychology \& Human Sexuality, $11,43-62$.

Money, D. W., \& Cain, R. E. (1997). Preservice elementary teachers' attitudes toward gay and lesbian parenting. Journal of School Health, 67, 236-241.

Nagoshi, J. L., Adams, K. A., Terrell, H. K., Hill, E. D., Brzuzy, S., \& Nagoshi, C. T. (2008). Gender differences in the correlates of homophobia and transphobia. Sex Roles, 59, 521-531.

Paige, R. U. (2005). Sexual orientation, parents \& children. Proceedings of the American Psychological Association, Incorporated. Retrieved December 1, 2011, from http://www. apa.org/about/governance/council/policy/parenting.aspx

Patterson, C. J. (2002). Lesbian and gay parenthood. In M. H. Bornstein (Ed.), Handbook of Parenting: Vol. 3. Being and becoming a parent (pp. 317-338). New York: Lawrence Erlbaum.

Patterson, C. J. (2006). Children of lesbian and gay parents. Current Directions in Psychological Science, 15, 241-244.
Patterson, C. J., \& Friel, L. V. (2000). Sexual orientation and fertility. In G. Bentley \& N. Mascie-Taylor (Eds.), Infertility in the modern world: Biosocial perspetives (pp. 238-260). Cambridge, UK: Cambridge University Press.

Perrin, E. C., \& Committee on Psychosocial Aspects of Child and Family Health. (2002). Technical report: Coparent and second-parent adoption by same-sex parents. Pediatrics, 109, 341-344.

Ryan, D., \& Martin, A. (2000). Lesbian, gay, bisexual, and transgender parents in the school system. School Psychology Review, 29, 207-216.

Tasker, F. (2005). Lesbian mothers, gay fathers and their children: A review. American Journal of Orthopsychiatry, 65, 203-215.

United States Census Bureau. (2003, February). Married and unmarried-partner households. Census 2000 special reports. Retrieved December 1, 2011, from http://www.census.gov/

Xavier, P., Mendes, F., Martins, E., \& Fernandes, R. (2011). A Homoparentalidade na perspetiva de estudantes do ensino superior. Trabalho apresentado no XI Congresso Internacional Galego-Portugués de Psicopedagoxía. Retrieved January, 3, 2012, from repositório.ipv.pt/handle/10400.19/982

\section{Anexo \\ Vinheta Descrevendo os Casais Adotantes}

Ana e Catarina são um casal há 10 anos, comprometidas uma com a outra e felizes. No entanto, têm uma vontade muito grande de serem mães, e como não podem ter filhos decidiram adotar. Ana e Catarina são ambas licenciadas, bem sucedidas profissionalmente e também muito queridas pelos amigos e familiares. Os pais de ambas estão entusiasmados com a ideia de serem avós, e disponibilizaram-se para ajudar no que for preciso para receber a criança na família. Ana e Catarina moram num apartamento com dois quartos espaçosos na mesma cidade onde ambas trabalham. Os amigos e colegas descrevem-nas como pessoas tranquilas, disponíveis, e atentas às necessidades dos outros, acreditando que reúnem a vontade e as características necessárias para serem boas mães. Têm alguma experiência de cuidar de crianças, especialmente dos sobrinhos de Ana. Depois de pensarem muito sobre o assunto, iniciaram o processo de adoção e frequentam as reuniões com a técnica responsável pelo recrutamento e seleção de famílias adotantes e estão muito entusiasmadas por virem a cumprir o desejo de serem mães. Estão a aguardar serem aceites como candidatas a adotarem uma criança.

Nota. Apenas os nomes das pessoas foram alterados de forma a descrever um casal heterossexual, um casal de lésbicas ou um casal gay. 